\title{
奥沙普秦丹皮酚酯的合成及抗炎活性研究
}



( ${ }^{c}$ 扬子江药业集团江苏紫龙药业有限公司 江苏常州 213100)

( ${ }^{d}$ Faculty of Science, King Abdulaziz University, Jeddah, 999088)

\begin{abstract}
摘要 奥沙普秦是临床常用抗炎药物，口服易造成胃肠穿孔，与其分子结构中羧酸基团引起的局部刺激密切相关. 丹 皮酚是生丹的有效成分，有抗炎、抗氧化的功效. 合成了奥沙普秦丹皮酚酯(OPE)，试图在避免胃肠道并发症的同时， 提高其抗炎效果. 通过 12-O-十四烷基佛波醇-13-乙酸酯(TPA)诱导的小鼠耳水肿模型评价了 OPE 的局部抗炎作用. 结 果显示局部应用 OPE 可有效改善 TPA 诱导的耳廓肿胀，抗炎效果是奥沙普秦的 2 倍，是丹皮酚的 4 倍. 而且 OPE 可有 效改善耳片组织 IL- $1 \beta$, IL-6 和 TNF- $\alpha$ 的表达，效果优于奥沙普秦和丹皮酚. 进一步研究显示 OPE 可通过阻断 I $\mathrm{B}$ 激酶 (IKK)活性来下调 kappa- $\mathrm{B}(\mathrm{NF}-\kappa \mathrm{B})$ 的活性.
\end{abstract}

关键词 奥沙普秦; 丹皮酚; 炎症; 耳廓肿胀模型

\section{Synthesis and Anti-inflammatory Effects of Oxaprozin-Paeonol Ester}

\author{
$\mathrm{Xu}, \mathrm{Xuetao}^{a}$ \\ Chen, $\mathrm{Jie}^{a}$ \\ Lin, Zhiqing $^{a}$ \\ Li, Dongli ${ }^{a}$ Zhang, Kun ${ }^{a}$ \\ Sheng, Zhaojun *,a \\ Wang, Shaohua *,a,b,c \\ Zhu, Shun \\ Asiri, Abdullah M. ${ }^{d}$ \\ $\left({ }^{a}\right.$ School of Biotechnology and Health Sciences, Wuyi University, Jiangmen 529020, Guangdong, China) \\ $\left({ }^{b}\right.$ School of Pharmacy, Lanzhou University, Lanzhou 730000, China) \\ ( ${ }^{C}$ Yangtze River Pharmaceutical Group Jiangsu Zilong Pharmaceutical Co., Ltd., Changzhou 213100, Jiangsu, China)



\begin{abstract}
Oxaprozin is a common anti-inflammatory drug in the clinic. Oral medication of oxaprozin potentially induces the GI perforation, which is caused by the local irritation of its carboxylic acid group. Paeonol is an active ingredient of peony, and has anti-inflammatory and anti-oxidant effects. So oxaprozin-paeonol ester (OPE) was designed to avoid the GI complications and enhence corresponding anti-inflammatory. The topical anti-inflammatory effects of OPE was evaluated in a 12-O-tetradecanoylphorbol-13-acetate (TPA) induced mouse ear edema model. The results showed that topical treatment of OPE could effectively improve the TPA-induced ear edema and its anti-inflammatory effect is 2 times higher than that of oxaprozin and 4 times than that of paeonol. Moreover, OPE treatment could effectively mitigate the expression of IL-1 $\beta$, IL-6, and TNF- $\alpha$, and its effect is better than that of oxaprozin or paeonol. Furthor study demonstrated that topical treatment of OPE

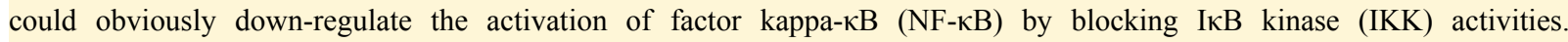
Accordingly, OPE might be used as a promising anti-inflammatory agent for inflammation-associated skin diseases.

Keywords Oxaprozin; Paeonol; Inflammatory; Ear edema mode
\end{abstract}

\section{Introduction}

Inflammation, the most widespread disorder, is part of the complex biological response of body tissues to harmful stimuli, including irritants, damaged cells, or pathogens. ${ }^{[13]}$ The chronic inflammation results in the prolonged and oxidative stress, even irreversible damage to tissues. $^{[4,5]}$ The most common therapeutic drugs for in-

\footnotetext{
* Corresponding authors. E-mail: wyuchemszj@126.com; wangshh@1zu.edu.cn

Received March 12, 2019; revised May 15, 2019; published online May 21, 2019.

Project supported by the Department of Education of Guangdong Province (Nos. 2017KTSCX185, 2017KSYS010, 2016KCXTD005), the Youth Team Fund of Wuyi University (No. 2016td01), and the National Natural Science Foundation of China (Nos. 21472077, 21772071).

广东省教育厅基金(Nos. 2017KTSCX185, 2017KSYS010, 2016KCXTD005)、五邑大学青年团队项目(No. 2016td01)、国家自然科学基金(Nos. 21472077, 21772071)资助项目.
} 
flammatory symptoms are non-steroidal anti-inflammatory drugs (NSAIDs). ${ }^{[6,7]}$ Despite their different structure, NSAIDs have a similar action mode by inhibiting the cyclooxygenase (COX) enzyme. ${ }^{[8,9]}$

Oxaprozin (a) with a chemical structure of 3-(4,5-diphenyl-1,3-oxazol-2-yl) propanoic acid is one of prominent NSAIDs (Figure 1). ${ }^{[10 \sim 14]}$ Oxaprozin exerts its pharmacological effect through the inhibition of COX-dependent inflammation pathway. ${ }^{[15]}$ Moreover, oxaprozin inhibits the $\mathrm{NF}-\kappa \mathrm{B}$ activation to regulate the inflammatory and immune mediators produced by I $\kappa \mathrm{B}$ kinase. But unfortunately, oral medication of oxaprozin potentially induces the gastric perforation, which is caused by the local irritation introduced by the carboxylic acid group of oxaprozin and the ion trapping mechanism from the lumen to mucosa. ${ }^{[16,17]}$ So far, lots of attempts to mask the carboxylic acid group of NSAIDs are inappropriate, leading to the failure in overcoming NSAIDs based GI complications.

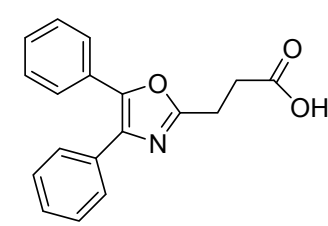

oxaprozin (a)

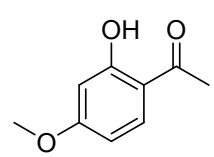

paeonol (b)
Figure 1 Chemical structure of oxaprozin and paeonol

Paeonol (b) is a primary bioactive component of moutan cortex radicis. Numerous researches indicated that paeonol displays excellent biological activity, such as anti-inflammatory, anti-oxidant, anti-bacterial, anti-diabetic, antiallergic, and anti-angiogenic. ${ }^{[18 \sim 20]}$ Also, paeonol has been used to treat skin pruritus, rheumatoid arthritis, and pain in China. ${ }^{[21]}$ The anti-inflammatory of paeonol is contributed to its regulation on reactive oxygen, iNOS, COX-2, and proinflammatory cytokines including TNF- $\alpha$ and IL- $1 \beta .^{[22]}$ In signal molecule level, some reports have shown that paeonol achieves its antioxidant and anti-inflammatory activity through inhibition or blocking the MAPK, ERK, and p38 signaling pathways. ${ }^{[23,24]}$

The structural modification of the carboxyl group of NSAIDs is an effective way to reduce the irritating side effects of GI perforation. ${ }^{[25]}$ Also, the introduction of antioxidant groups might enhance anti-inflammatory effects of maternal skeleton. ${ }^{[26]}$ To effectively manage inflammatory diseases and overcome the oxaprozin based GI complications, there is a urgent need to intervene an anti-inflammatory and anti-oxidant group. Hence, the synthesis of oxaprozin-paeonol ester (OPE) exploiting the anti-inflammatory and anti-oxidant capacity of paeonol to mask the carboxylic acid group of oxaprozin was reported.

\section{Results and discussion}

\subsection{Synthesis and characterization of OPE}

As shown in Scheme 1, OPE was prepared by the reaction between oxaprozin and paeonol in yield of $80 \%$, and used for the following biological experiments. Next, the biological properties of oxaprozin, paeonol and OPE were evaluated.

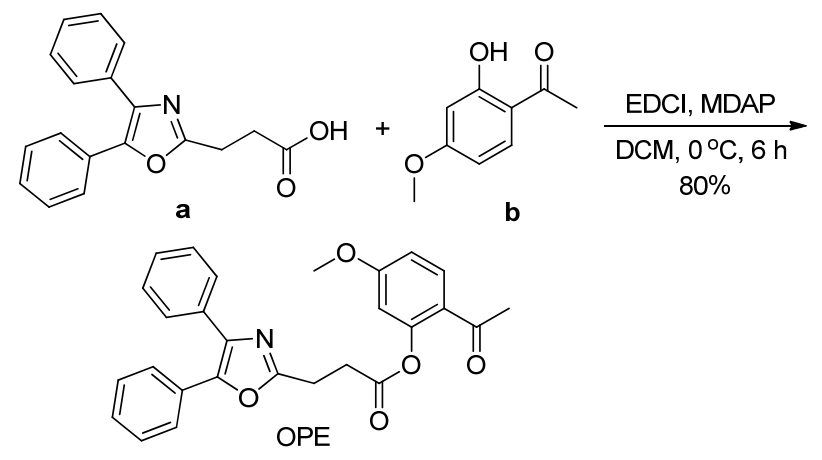

Scheme 1 Synthesis of OPE

\subsection{Effect of OPE on TPA-induced ear edema}

In recent years, TPA-induced ear edema has been developed into a mature animal model of inflammation due to its advantages of simple operation, stable model, and often used to evaluate the anti-inflammatory activity of compound. ${ }^{[27 ~ 29]}$ So the effect of OPE on TPA-induced ear edema was investigated. According to our previous publications, the concentration of TPA was selected as 0.008 $\mathrm{nmol} \bullet \mathrm{L}^{-1}$, and compound concentration was selected as $0.75 \mu \mathrm{mol} \cdot \mathrm{L}^{-1} \cdot{ }^{[30,31]}$ As shown in Figure 2, topical treatment of TPA alone led to a significant increase in the weight of ear punches from $14.9 \mathrm{mg}$ to $40.4 \mathrm{mg}$, which verified that TPA could stimulate the progress of inflammatory. While pretreatment with oxaprozin and paeonol, OPE could obviously reduce the weight of ear punches compared to TPA treatment alone. And the inhibitory effect of OPE on TPA-induced ear edema model was $61.8 \%$, which was about 2 times higher than that of oxaprozin and 4 times than that of paeonol. These results indicate that OPE potential plays a synergy of oxaprozin and paeonol on treat TPA-induced inflammatory.

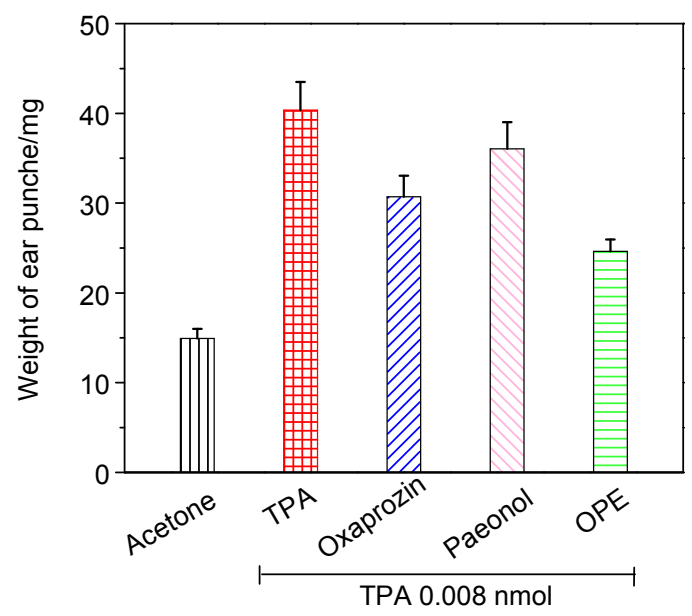

Figure 2 Effect of oxaprozin, paeonol, OPE on TPA-induced ear edema

Data are presented as mean \pm SE $(n=4)$. Compared to TPA alone, $* P<$ 0.05 


\subsection{Effect of OPE on TPA-induced histological ap- pearance}

When stimulated with TPA, the ear skin appears a significant increase of skin thickening, which is linked with the edema, proliferation of epidermal keratinocytes, and increase of vascular permeability. ${ }^{[32]}$ The disorders of inflammatory tissue can be evaluated by its histological appearance. In control tissues only treated with acetone (Figure 3a), there was a normal performance in epidermal layer without any significant lesion. When stimulated with TPA, the ear occurred obviously inflammation leading to epidermal hyperplasia, hyperkeratosis, and leukocyte infiltration of tissue (Figure 3b), which is consistent with the results of previous report. ${ }^{[30]}$ It is amazing that topical pretreatment with oxaprozin, paeonol, and OPE obviously prevented the feature of inflammatory responses (Figures $3 \mathrm{c} \sim 3 \mathrm{e})$. Those results revealed that OPE could effectively relieve TPA-induced inflammatory.

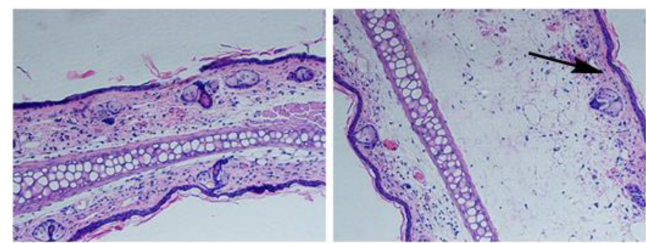

(a) Acetone

(b) TPA



(c) Oxaprozin

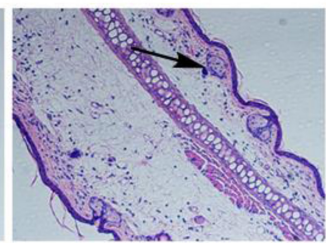

(d) Paeonol

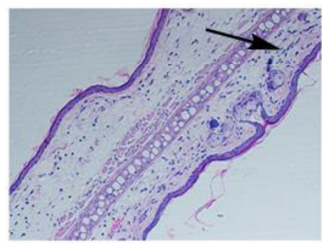

(e) OPE

Figure 3 Effect of oxaprozin, paeonol, OPE on TPA-induced histological changes of ear edema (H\&E staining)

Data are presented as mean \pm SE $(n=4)$. Compared to TPA alone, ${ }^{*} P<$ 0.05. Magnification $200 \times$

\subsection{Effects of OPE on TPA-induced TNF- $\alpha, \mathrm{IL}-1 \beta$, and IL-6}

Cytokines are protein molecules, which help to regulate the immune response of body against infection and trauma. ${ }^{[33,34]}$ After been stimulated, cells produce a variety of proinflammatory cytokines including TNF- $\alpha$, IL- $1 \beta$, and IL- 6 to accelerate the process of inflammatory. ${ }^{[34,35]}$ Then, we investigated whether or not OPE has effect on TPA-induced TNF- $\alpha$, IL- $1 \beta$, and IL-6. Wu et $a l .{ }^{[25]}$ verified that TPA induced the secretion of inflammatory factors. As shown in Figure 4b, TPA stimulation resulted in the obvious increase on the expression of TNF- $\alpha$, IL- $1 \beta$, and IL-6 compared with control (Figure 4a). However, the topical pretreatment with oxaprozin, paeonol, and OPE could markedly reduce the expression of TPA-induced TNF- $a$, IL- $1 \beta$, and IL-6 (Figures $4 \mathrm{c} \sim 4 \mathrm{e}$ ). Also the effects of OPE on TPA-induced TNF- $\alpha$, IL- $1 \beta$, and IL- 6 were higher than those of oxaprozin and paeonol. These results also confirmed that inflammatory process was closely related to the expression of TNF- $\alpha$, IL- $1 \beta$, and IL- 6 .

\subsection{Effects of OPE on TPA-induced NF-kB activation}

Nuclear factor $\kappa \mathrm{B}(\mathrm{NF}-\kappa \mathrm{B})$ consist p50, p52, p65, Rel, and RelB is a nuclear transcription factor that regulates expression of a large number of genes. They are critical for the regulation of apoptosis, viral replication, tumorigenesis, inflammation, and various autoimmune diseases. ${ }^{[36,37]}$ Cytokines including TNF- $\alpha$, IL- $1 \beta$, and IL-6 involved in inflammation are regulated by NF- $\kappa \mathrm{B} \cdot{ }^{[38,39]}$ Herein, it is very important to evaluate how OPE effects the TPA-induced NF- $\kappa B$ activation. Here, the effect of OPE on p65 was investigated. After TPA stimulated (Figure 5b), p65 was evoked nuclear translocation to the nucleus indicating an obviously increased expression. Figures $5 \mathrm{c} \sim 5 \mathrm{e}$ also show that topical pretreatment with oxaprozin, paeonol, and OPE could strongly block the expression of TPA-induced p65. Moreover, topical pretreatment with oxaprozin, paeonol, and OPE also markedly decrease the expression of TPA-induced phosphor-p65, which contributes to its transcriptional activity (Figures $5 \mathrm{c} \sim 5 \mathrm{e}$ ). Thence, the anti-inflammation effect of OPE is linked to its inhibition ability on NF- $\kappa \mathrm{B}$ activation.

\subsection{Effects of OPE on TPA-induced IKK}

It has been demonstrated that phosphorylation of I $\mathrm{KB}$ proteins including $I \kappa B \alpha$ is essential for NF- $\kappa$ B activation. The degradation of $\mathrm{I} \kappa \mathrm{B}$ arouses $\mathrm{NF}-\kappa \mathrm{B}$ to translocate into nucleus. ${ }^{[40]}$ The IкB kinase (IKK) plays key roles in phosphorylating $\mathrm{I} \kappa \mathrm{B} \alpha^{[41]}$. And IKK has been reported to highly relate with the NF- $\kappa \mathrm{B}$ activation. ${ }^{[42]}$ Then the effect of OPE on TPA-induced IKK was investigated. As described in Figure $6 \mathrm{~b}$, TPA stimulation resulted in the degradation of $\mathrm{I} \kappa \mathrm{B} \alpha$ accompanies with its phosphorylation. The topical pretreatment with oxaprozin, paeonol, and OPE markedly suppressed the phosphorylation of $\mathrm{I} \kappa \mathrm{B} \alpha$ (Figures $6 \mathrm{c} \sim 6 \mathrm{e}$ ). Moreover, topical pretreatment with oxaprozin, paeonol, and OPE obviously reduced the TPA-induced IKK activity (Figures $6 \mathrm{a} \sim 6 \mathrm{e}$ ). The results suggested that OPE inhibited activation of NF- $\mathrm{KB}$ by blocking IKK activities.

\subsection{Effects of OPE on TPA-induced Akt}

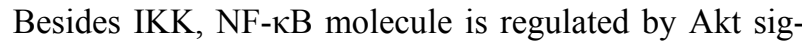
nal pathway. Activated Akt signal is also involved in the phosphorylation and degradation of $\mathrm{I} \kappa \mathrm{B}$, resulting in the NF- $\kappa \mathrm{B}$ activation. ${ }^{[43]}$ In addition, Akt signal pathway is involved in the mediation of pro-inflammatory cytokines including TNF- $\alpha$, IL, and IFN. ${ }^{[44 \sim 46]}$ So the effect of OPE on Akt signal pathway was investigated. As illustrated in Figure 7, TPA stimulation caused significant increases on 


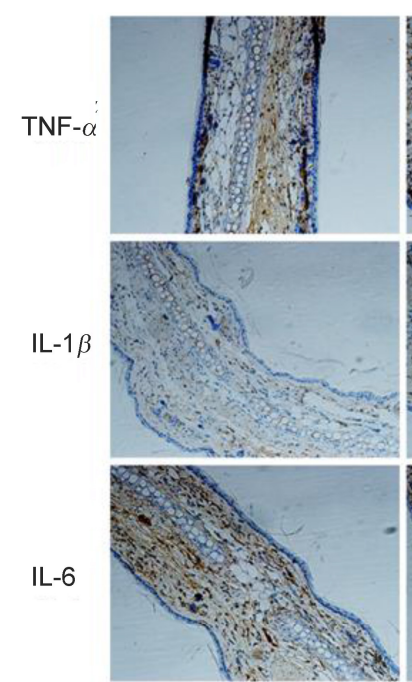

(a) Acetone


(b) TPA
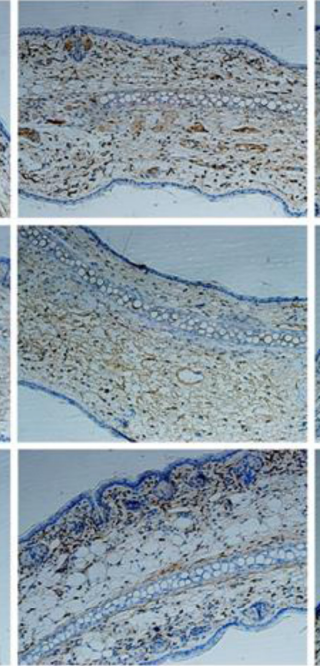

(c) Oxaprozin


(d) Paeonol

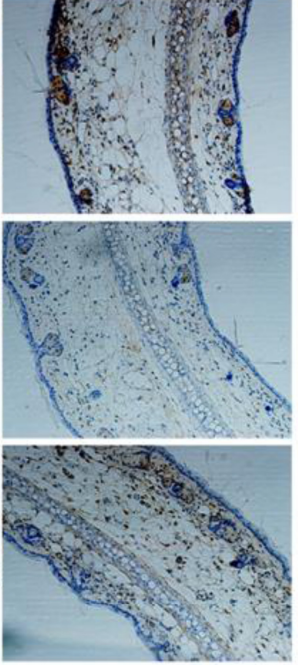

(e) OPE



Figure 4 Effect of oxaprozin, paeonol, OPE on TPA-induced TNF- $\alpha$, IL-1 $\beta$, and IL-6 Data are presented as mean $\pm \operatorname{SE}(n=4)$. Compared to TPA alone, $* P<0.05$. Magnification $200 \times$

expressions and phosphorylation of Akt. And topical pretreatment with oxaprozin, paeonol, and OPE significantly inhibited the TPA-induced Akt activity (Figures 7c 7 e). All the results revealed that OPE exerted its anti-inflammatory through down-regulating the $\mathrm{NF \kappa B}$ activation by blocking Akt/IKK activities (Figure 8).

\section{Conclusions}

Inspired by paeonol, a natural antioxidants and antiulcerogenic, OPE had been designed and synthesized to avoid the GI complications of oxaprozin. In TPA-induced mouse ear edema model, OPE showed more beneficial effects on anti-inflammatory than that of oxaprozin or paeonol, including swelling, histological change, and release of proinflammatory cytokines. In addition, this study also revealed that the anti-inflammatory of OPE was associated with its ability to down-regulate activation of NF- $\mathrm{BB}$ by blocking Akt/IKK activities. Currently, the development of more potent lead compounds is ongoing in the same lab.

\section{Experimental section}

\subsection{Materials}

Oxaprozin and paeonol were obtained from Shanghai Aladdin Bio-Chem Technology Co., LTD (China). 12-OTetradecanoylphorbol 13-acetate (TPA) was purchased from Sigma Chemical Co. (USA). ${ }^{1} \mathrm{H}$ NMR and ${ }^{13} \mathrm{C}$ NMR spectra of OPE were recorded on a Bruker AM-600 NMR spectrometer (USA) in $\mathrm{CDCl}_{3}$. Elemental analysis was conducted with a Series II 2400 elemental analyzer (USA). Melting point was measured with automatic melting point instrument (China). IR was recorded using a Shimadzu fourier transform infrared spectrometer (Japan). TNF-a, IL-1 $\beta$, IL-6, anti-rabbit, anti-mouse horseradish peroxidase (HRP)-conjugated secondary antibodies, anti-Ser536 p65, antiphospho-Ser536 p65 antibodies, antiphospho-Ser32 IkB- $\alpha$, anti-IKK, anti-Ser473 Akt, antiphospho-Ser473 Akt were obtained from Beyotime Biotechnology Co. (China). Other chemicals used were obtained form available commercially. 


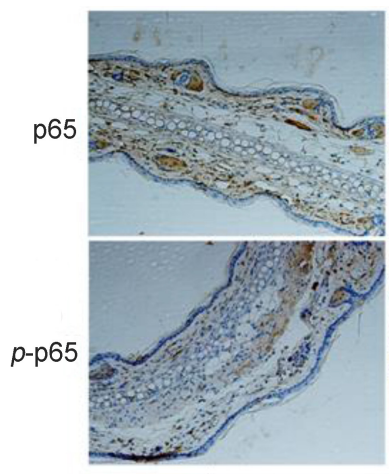

(a) Acetone

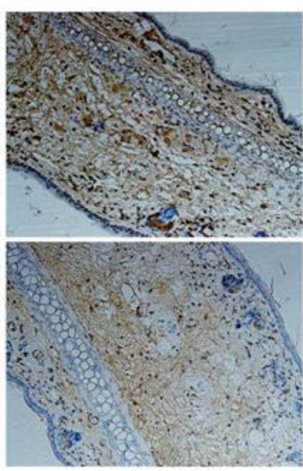

(b) TPA

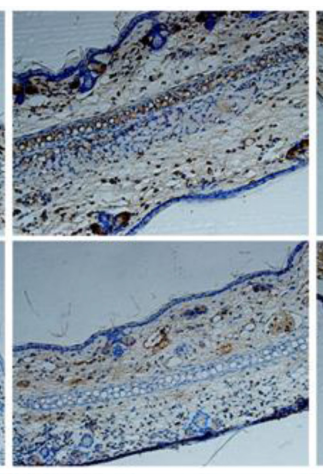

(c) Oxaprozin

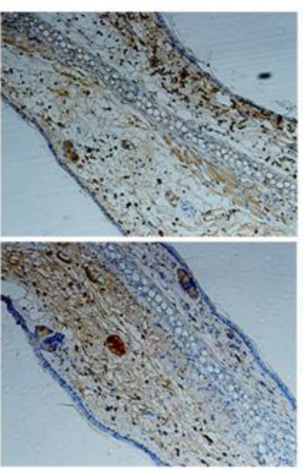

(d) Paeonol

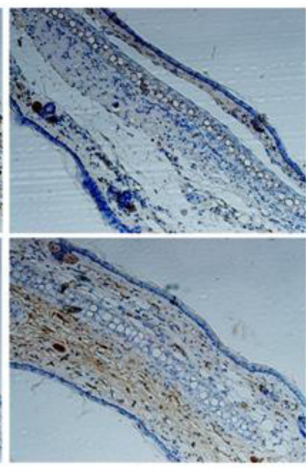

(e) OPE

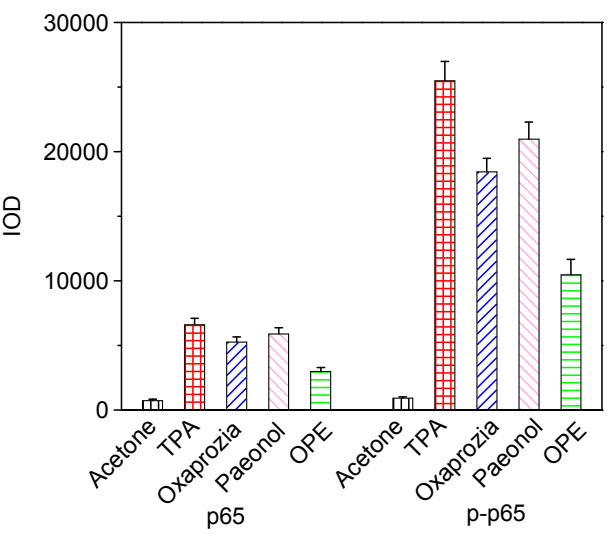

Figure 5 Effect of oxaprozin, paeonol, OPE on TPA-induced NF- $\kappa$ B activation Data are presented as mean $\pm \operatorname{SE}(n=4)$. Compared to TPA alone, ${ }^{*} P<0.05$. Magnification $200 \times$



a: Acetone
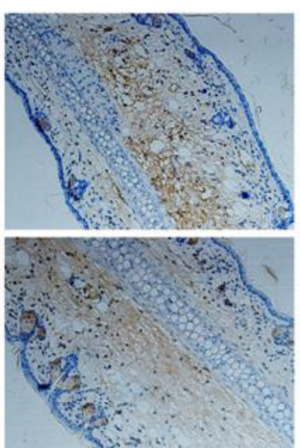

b: TPA


c: Oxaprozin


d: Paeonol

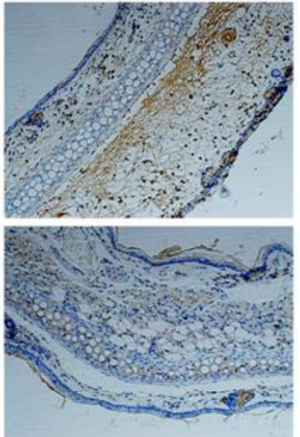

e: OPE



Figure 6 Effect of oxaprozin, paeonol, OPE on TPA-induced IKK

Data are presented as mean $\pm \operatorname{SE}(n=4)$. Compared to TPA alone, $* P<0.05$. Magnification $200 \times$ 


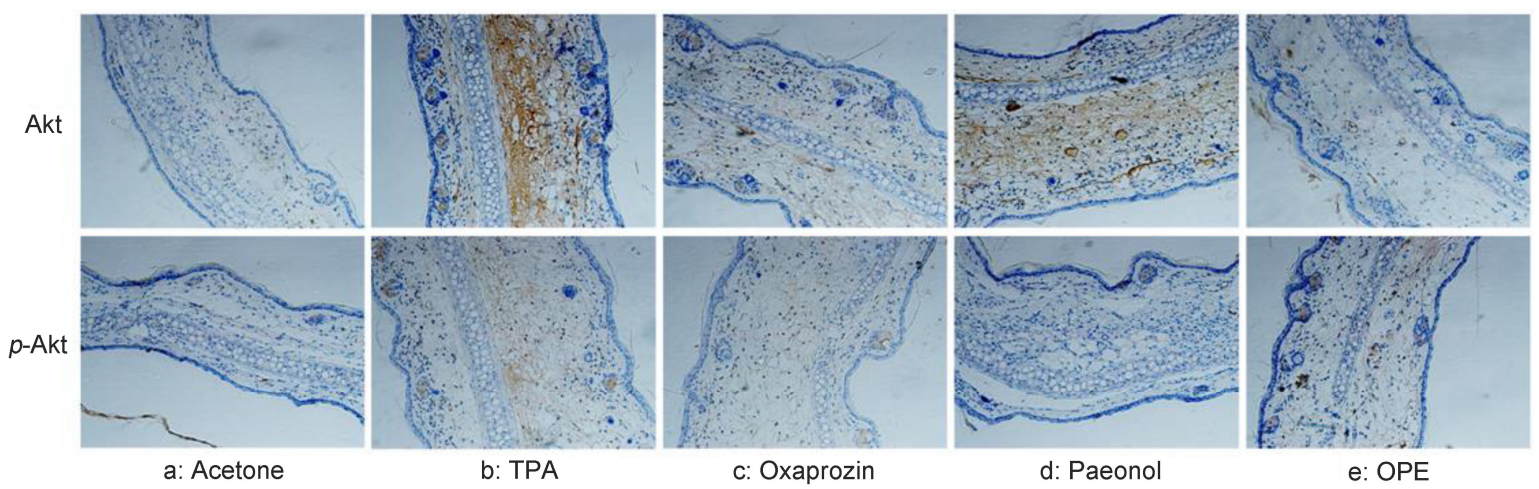

Figure 7 Effect of oxaprozin, paeonol, OPE on TPA-induced Akt Data are presented as mean $\pm \operatorname{SE}(n=4)$. Compared to TPA alone, ${ }^{*} P<0.05$. Magnification $200 \times$

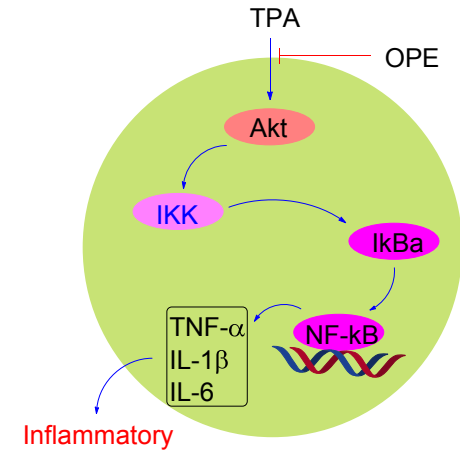

Figure 8 A model of OPE modulation of TPA-induced signal transduction pathways in mouse skin in vivo

\subsection{Synthesis and characterization of OPE}

Oxaprozin (146.8 mg, $0.5 \mathrm{mmol}$ ), paeonol (84.2 mg, 0.5 mmol), EDCI (144.5 mg, $0.75 \mathrm{mmol})$ and DMAP (61.4 $\mathrm{mg}, 0.5 \mathrm{mmol}$ ) were mixed in dichloromethane (DCM, 5 $\mathrm{mL}$ ) at $0{ }^{\circ} \mathrm{C}$. The mixture was stirred for $6 \mathrm{~h}$ at $0{ }^{\circ} \mathrm{C}$, then quenched with water. The aqueous layer was extracted three times with EtOAc and the combined organic layers were washed with brine, dried over sodium sulfate, and evaporated to dryness and purified by column chromatography to afford OPE as a white solid (182.4 $\mathrm{mg}, 80 \%)$. m.p. $114 \sim 115.5{ }^{\circ} \mathrm{C} ;{ }^{1} \mathrm{H}$ NMR $\left(400 \mathrm{MHz}, \mathrm{CDCl}_{3}\right) \delta: 7.75$ $(\mathrm{d}, J=8.8 \mathrm{~Hz}, 1 \mathrm{H}), 7.61 \sim 7.54(\mathrm{~m}, 2 \mathrm{H}), 7.55 \sim 7.49(\mathrm{~m}$, $2 \mathrm{H}), 7.33 \sim 7.17(\mathrm{~m}, 6 \mathrm{H}), 6.74(\mathrm{dd}, J=8.8,2.5 \mathrm{~Hz}, 1 \mathrm{H})$, $6.54(\mathrm{~d}, J=2.5 \mathrm{~Hz}, 1 \mathrm{H}), 3.67(\mathrm{~s}, 3 \mathrm{H}), 3.27$ (t, $J=6.9 \mathrm{~Hz}$, $2 \mathrm{H}), 3.18(\mathrm{t}, \mathrm{J}=6.9 \mathrm{~Hz}, 2 \mathrm{H}), 2.44(\mathrm{~s}, 3 \mathrm{H}) ;{ }^{13} \mathrm{C}$ NMR $(101$ $\left.\mathrm{MHz}, \mathrm{CDCl}_{3}\right) \delta: 195.63,170.63,163.79,161.62,151.42$, $145.56,135.15,132.48,128.98,128.64,128.55,128.47$, $128.06,127.93,126.54,122.86,112.08,109.06,55.62$, 31.33, 29.70, 29.06; IR (KBr) v: 3065, 2915, 2848, 1756, 1576, 1496, 1425, 1201, 1139, 914, 822, 765, $693 \mathrm{~cm}^{-1}$. Anal. calcd for $\mathrm{C}_{27} \mathrm{H}_{23} \mathrm{NO}_{5}$ : C 73.46, H5.25, N 3.17; found C 73.38, H 5.26, N 3.12.

\subsection{Animals}

Female ICR mice at 6 weeks old were supplied from Guangdong Medical Laboratory Animal Center (China). All mices were housed in condition of $(25 \pm 1){ }^{\circ} \mathrm{C}$ at $50 \%$ relative humidity, fed with food and water ad libitum. This experiments were maintained in accordance with the guidelines of Guangdong Medical Laboratory Animal Center, and approved by the institutional ethical committee of Wuyi University.

\subsection{TPA-induced ear edema in mice}

Oxaprozin, paeonol, OPE, and TPA were dissolved in acetone. Mice were randomly divided into 5 groups, and each group had four mice. For TPA-induced mouse ear edema model, the right ears of mice were topical treated with acetone, oxaprozin, paeonol, and OPE respectively, and stimulated with TPA after $30 \mathrm{~min}$. The mice un-stimulated with TPA were set as control. All mice were euthanized after $6 \mathrm{~h}$, and the ear punches of $9 \mathrm{~mm}$ diameter from mice right ears were taken and weighed. Then inhibitory effects $=\left[\left(W_{\mathrm{a}}-W_{\mathrm{b}}\right) /\left(W_{\mathrm{a}}-W_{\mathrm{c}}\right)\right] \times 100 \%$. Where, $W_{\mathrm{a}}$ is the weight of ear treated with TPA alone, $W_{\mathrm{b}}$ is the weight of ear treated with TPA + test compound, $W_{\mathrm{c}}$ is the weight of ear treated with acetone alone.

\subsection{Histological appearance of mice ears}

Mice ear punches were selected and fixed in $10 \%$ formalin. After decalcified in EDTA buffer and subjected dehydration, ear punches were embedded into paraffin. The slice of $4 \mu \mathrm{m}$ was serially sectioned, and stained with routinely $H \& E$ staining. Then the histological changes of mice ear were observed under a microscope.

\subsection{Determination of TNF- $\alpha$, IL-1 $\beta$, and IL-6}

The TNF- $\alpha$, IL- $1 \beta$, and IL- 6 levels were determined as described previously. ${ }^{[47,48]}$ After deparaffinized treatment, the ear slices were incubated in $\mathrm{H}_{2} \mathrm{O}_{2}(1.2 \%)$. Ear slices then were treated with the primary antibody of proliferating cell nuclear antigen $(1: 100)$ overnight at $4{ }^{\circ} \mathrm{C}$. After washed, the ear slices were incubated into biotin-conjugated horseradish peroxidase antibody $(1: 200)$ for $1 \mathrm{~h}$ at $25{ }^{\circ} \mathrm{C}$. Then the peroxidase was detected with 3,3-diaminobenzidine tetrahydrochloride reactions, resulting to a brown label in ear tissue. For each ear slice, the positive staining cell numbers were counted in randomly five different fields.

4.7 Assay of p65, phospho-p65, phospho-IKBa, IKK, Akt, phospho-Akt

The effects of OPE on the NF- $\kappa \mathrm{B}$, Akt, IKK signal pathway were measured by immunohistochemistry analy- 
sis as described in our previous work. ${ }^{[49,50]}$ Mice ears were selected, fixed, and embedded in paraffin. The sectioned ear slices of $4 \mu \mathrm{m}$ were stained with routinely staining method, and the positive staining cell numbers were counted in randomly five different fields.

\subsection{Scoring of the expression of biomarkers}

The assays of IL-1 $\beta$, IL-6, TNF- $\alpha$, p65, p-p65, p-IкB $\alpha$, IKK, Akt, and p-Akt were detected using integrated optical density (IOD) following semi-quantitative scoring system ${ }^{[51]}$. The staining intensity was scored as follows: 0 , no staining; $1+$, faint; $2+$, moderate; $3+$, strong. The staining extent was graded as follows: 0 , no staining; $1+, \leqslant$ $25 \%$ of cells positive; $2+, 26 \% \sim 50 \%$ of cells positive; 3 ,$+ \geqslant 51 \%$ of cells positive. ${ }^{[52]}$

\subsection{Statistical analysis}

All results are presented as mean $\pm \mathrm{SE}$. Comparison between groups was calculated with one-way analysis of variance (ANOVA) followed by Dunnett's t-test. $P<0.05$ was considered indicative of significance.

\section{References}

[1] Talaat, R.; El-Sayed, W.; Agwa, H. S.; Gamal-Eldeen, A. M.; Moawia, S.; Zahran, M. A. H. Chem.-Biol. Interact. 2015, 238, 74.

[2] McInnes, I. B.; Schett, G. Nat. Rev. Immunol. 2007, 7, 429.

[3] Shin, J. S.; Choi, H. E.; Kim, S. D.; Lee, Y. S.; Cho, Y. W.; Lee, K. T. Chem. Biol. Interact. 2014, 224, 68.

[4] Wu, J.; Chu, C. C. J. Mater. Chem. B 2013, $1,353$.

[5] Wu, J.; Chu, C. C. Acta Biomater. 2012, 8, 4314.

[6] Rao, P. P. N.; Kabir, S. N; Mohamed, T. Pharmaceuticals 2010, 3, 1530 .

[7] Rainsford, K. D.; Whitehouse, M. W. Inflammopharmacology 2006, 14,150 .

[8] Robak, P.; Smolewski, P.; Robak, T. Leuk Lymphoma 2008, 49, 1452 .

[9] Macario, A.; Lipman, A. G. Pain Med. 2001, 2, 336.

[10] al-Faks, M. A.; Pugh, M. C. Orthop. Rev. 1995, 21, 558.

[11] Bozic, B. D.; Rogan, J. R.; Poleti, D. D.; Trisovic, N. P.; Uscumlic, G. S. Chem. Pharm. Bull. 2012, $60,865$.

[12] Rainsford, K. D.; Omar, H.; Ashraf, A.; Hewson, A. T. R.; Bunning, A. D.; Rishiraj, R.; Shepherd, P.; Seabrook, R. W. Inflammopharmacology 2002, 10, 185 .

[13] Lopes-de-Araújo, J.; Neves, A. R.; Gouveia, V. M.; Moura, C. C.; Nunes, C.; Reis, S. Pharm. Res. 2016, 33, 301.

[14] Peesa, J. P.; Atmakuri, L. R.; Yalavarthi, P. R.; Venkata, B. R. M.; Rasheed, A.; Pachava, V. Arch. Pharm. Chem. Life Sci. 2017, 351, e1700256.

[15] Dallegri, F.; Bertolotto, M.; Ottonello, L. Exp. Opin. Ther. 2005, 1, 777.

[16] Peesa, J. P.; Yalavarthi, P. R.; Rasheed, A.; Mandava, V. B. J. Acute Dis. 2016, 1, 364.

[17] Bandgar, B. P.; Sarangdhar, R. J.; Viswakarma, S.; Ahamed, F. A. J. Med. Chem., 2011, 1, 1191.

[18] Chou, T. C. Br. J. Pharmacol. 2003, 139, 1146

[19] Huang, T. J.; Chuang, H.; Liang, Y. C.; Lin, H. H.; Horng, J. C.; Kuo, Y. C.; Chen, C. W.; Tsai, F. Y.; Yen, S. C.; Chou, S. C.; Hsu, M. H. Eur. J. Med. Chem. 2015, 90, 428.

[20] Nizamutdinova, I. T.; Jin, Y. C.; Kim, J. S.; Yean, M. H.; Kang, S. S.; Kim, Y. S.; Lee, J. H.; Seo, H. G.; Kim, H. J.; Chang, K. C. Planta Med. 2008, 74, 8.

[21] Huang, L.; Zhang, B.; Yang, Y.; Gong, X.; Chen, Z.; Wang, Z.; Zhang, P.; Zhang, Q. Bioorg. Med. Chem. Lett. 2016, 26, 5218.
[22] Zhang, H.; Chen, S.; Deng, X.; Yang, X.; Huang, X. Diabetes Res. Clin. Pract. 2006, 74, 194.

[23] Nizamutdinova, I. T.; Oh, H. M.; Min, Y. N.; Park, S. H.; Lee, M. J.; Kim, J. S.; Yean, M. H.; Kang, S. S.; Kim, Y. S.; Chang, K. C.; Kim, H. J. Int. Immunopharmacol. 2007, 7, 343.

[24] Jin, X.; Wang, J.; Xia, Z. M.; Shang, C. H.; Chao, Q. L.; Fan, H. Y.; Chen, D. Q.; Qiu, F.; Zhao, F. Inflammation 2016, 39, 434.

[25] Wu, P. P.; He, H.; Hong, W. D.; Wu, T.; Huang, G.; Zhong, Y.; Tu B.; Gao, M.; Zhou, J.; Zhao, S.; Li, D.; Xu, X. T.; Sheng, Z.; Ward, S. A.; O'Neill, P. M.; Zhang, K. Infect. Drug Resist. 2018, 11, 1945.

[26] Xu, L.; Mou, X. Q.; Chen, Z. M.; Wang, S. H. Chem. Commun. 2014, 50, 10676.

[27] Hernández, V.; Máñez, S.; Recio, M. C.; Giner, R. M.; Ríos, J. L. Eur. J. Pharm. Sci., 2005, 26, 162.

[28] Mehrotra, A.; Shanbhag, R.; Chamallamudi, M. R.; Singh, V. P.; Mudgal, J. Eur. J. Pharm. 2011, 666, 80.

[29] Hernández, I.; Márquez, L.; Martínez, I.; Dieguez, R.; Delporte, C.; Prieto, S.; Molina-Torres, J.; Garrido, G. J. Ethnopharmacol. 2009, $124,649$.

[30] Xu, X. T.; Mou, X. Q.; Xi, Q. M.; Liu, W. T.; Liu, W. F.; Sheng, Z. J.; Zheng, X.; Zhang, K.; Du, Z. Y.; Zhao, S. Q.; Wang, S. H. Bioorg. Med. Chem. Lett. 2016, 26, 5334.

[31] Xu, X. T.; Huang, D. Y.; Liu, W. F.; Sheng, Z. J.; Liang, K. Y.; Li, D. L.; Zhao, D.; Ma, Y.; Zhang, K.; Hayat, T.; Alharbif, N. S.; Li, W. K. RSC Adv., 2017, 7, 34699.

[32] Rao, T. S.; Currie, J. L.; Shaffer, A. F.; Isakson, P. C. Inflammation 1993, 17, 723.

[33] Hauser, C.; Dayer, J. M.; Jaunin, F.; de Rochemonteix, B.; Saurat, J. H. Cell. Immunol. 1986, 100, 89.

[34] Kock, A.; Schwarz, T.; Kirnbauer, R.; Urbanski, A.; Perry, P.; Ansel, J. C.; Luger, T. A. J. Exp. Med. 1990, 172, 1609.

[35] Kupper, T. S.; Ballard, D. W.; Chua, A. O.; McGuire, J. S.; Flood, P. M.; Horowitz, M. C.; Langdon, R.; Lightfoot, L.; Gubler, U. J. Exp. Med. 1986, 164, 2095.

[36] Singh, S.; Aggarwal, B. B. J. Biol. Chem. 1995, 270, 10631.

[37] Han, S. S.; Keum, Y. S.; Seo, H. J.; Chun, K. S.; Lee, S. S.; Surh, Y. J. Cancer Lett. 2001, 164, 119.

[38] Kim, S. O.; Kundu, J. K.; Shin, Y. K.; Park, J. H.; Cho, M. H.; Kim, T. Y.; Surh, Y. J. Oncogene 2005, 24, 2558.

[39] Zandi, E.; Rothwarf, D. M.; Delhase, M.; Hayakawa, M.; Karin, M. Cell 1997, 91, 243.

[40] Li, Z. W.; Chu, W.; Hu, Y.; Delhase, M.; Deerinck, T.; Ellisman, M.; Johnson, R.; Karin, M. J. Exp. Med. 1999, 189, 1839.

[41] Karin, M.; Delhase, M. Semin. Immunol. 2000, 12, 85.

[42] Carpenter, C. L.; Cantley, L. C. Curr. Opin. Cell Biol. 1996, 8, 153

[43] Karin, M. Oncogene 1999, 18, 6867.

[44] Shimamura, H.; Terada, Y.; Okado, T.; Hiroyuki, T.; Inoshita, S.; Sadak, S. J. Am. Soc. Nephrol. 2003, 14, 1427.

[45] Selvaraj, S. K.; Giri, R. K.; Perelman, N.; Johnson, C.; Malik, P.; Kalra, V. K. Blood 2003, 102, 1515.

[46] Hatcher, H.; Planalp, R.; Cho, J.; Torti, F. M.; Torti, S. V. Cell. Mol. Life Sci. 2008, 65, 1631.

[47] V. Stefano, D. M. Paolo, S. Rossana and L. Luisa, J. Drugs Dermatol. 2009, 8,537 .

[48] Liu, W. F.; Li, Y. L.; Zhang, K.; Du, Z. Y. Food Funct. 2015, 6, 3712.

[49] Liu, W. F.; Li, Y. L.; Zheng, X.; Zhang, K.; Du, Z. Med. Chem. Commun. 2015, 6, 1605.

[50] Liu, W. F.; Li, Y. L.; Yue, Y.; Zhang, K.; Chen, Q.; Wang, H. Q.; Lu, Y. J.; Huang, M. T.; Zheng, X.; Du, Z. Y. Bioorg. Med. Chem. Lett. 2015, 25, 3044.

[51] Kraan, M. C.; Haringman, J. J.; Ahern, M. J.; Breedveld, F. C.; Smith, M. D.; Tak, P. P. Rheumatology 2000, 39, 43.

[52] Ouyang, N.; Williams, J. L.; Tsioulias, G. J.; Gao, J. J.; Iatropoulos, M. J.; Kopelovich, L.; Kashfi, K.; Rigas, B. Cancer Res. 2006, 66, 4503.

(Li, L.; Fan, Y.) 